Pathophysiology

of Haemostasis and Thrombosis
Pathophysiol Haemost Thromb 2005;34:269-273

DOI: $\underline{10.1159 / 000093106}$
Received: May 18, 2005

Accepted after revision: December 7, 2005

\title{
Evaluation of Platelet Indexes in Patients with Aortic Aneurysm
}

\author{
Akihiro Ihara $^{\mathrm{a}, \mathrm{c}, \mathrm{f}}$ Kengo Matsumoto ${ }^{\mathrm{b}}$ Toshiharu Kawamoto $^{\mathrm{b}}$ \\ Saburou Shouno $^{d}$ Jun Kawamoto $^{\mathrm{e}}$ Akira Katayama $^{\mathrm{e}}$ Masao Yoshitatsu $^{\mathrm{e}}$ \\ Hironori Izutani ${ }^{\mathrm{e}}$ \\ Departments of ${ }^{\mathrm{a}} \mathrm{Hematology}$ and ${ }^{\mathrm{b}} \mathrm{C}$ ardiology, Institutes of ${ }^{\mathrm{c}} \mathrm{Clinical}$ Research and ${ }^{\mathrm{d}} \mathrm{Clinical}$ Laboratory, and \\ e Department of Cardiovascular Surgery, National Hospital Organization Kure Medical Center, Kure, and \\ ${ }^{f}$ Department of Internal Medicine, National Hospital Organization Kamo Psychiatry Medical Center, \\ Higashi-Hiroshima, Japan
}

\section{Key Words}

Platelet index $\cdot$ Mean platelet volume $\cdot$ Platelet-large

cell ratio $\cdot$ Platelet distribution width $\cdot$ Aneurysm, aortic

\begin{abstract}
The purpose of this study was to investigate whether platelet indexes [platelet count, mean platelet volume (MPV), platelet-large cell ratio (P-LCR), and platelet distribution width (PDW)] could serve as diagnostic tools to evaluate the potential significance of platelet heterogeneity on thrombus formation. Blood samples were obtained from 54 patients with aortic aneurysm ( $A A$; mean age 73 years; 40 males, 14 females), from 120 agematched controls ( $A C$; mean age 74 years; 61 males, 59 females), and from 38 young controls (YC; mean age 30 years; 20 males, 18 females). We measured the blood platelet indexes using an automated counter, as well as plasma D-dimer and thrombin-antithrombin III complex (TAT) using ELISA. The AA patients were divided into two groups, group $A$ (platelet count more than $150 \times$ $10^{9} / \mathrm{l}, \mathrm{n}=36$ ) and group $\mathrm{B}$ (platelet count below $150 \times$ $\left.10^{9} / \mathrm{l}, \mathrm{n}=18\right)$. There was no difference in the platelet count between AC and YC. However, P-LCR was signifi-
\end{abstract}

cantly higher $(p=0.0113)$ in AC. MPV and PDW were also higher, but not significantly so. The platelet count was not different between group A and AC. MPV $(p=0.0024$ and $<0.0001$, respectively), P-LCR $(p<0.0012$ and $<0.0001$, respectively) and PDW ( $p=0.0006$ and 0.0005 , respectively) were significantly lower in group $A$ than in group $B$ and AC. The platelet indexes were significantly lower in the $54 \mathrm{AA}$ patients than in the AC. There were significant inverse relationships between the platelet count and other indexes in the AC and 54 AA patients; however, no relationships were observed in group $A, B$ and YC. The D-dimer and TAT levels were significantly higher in group $B$ than in groups $A$ and $Y C$. In conclusion, these findings suggest that large platelets decrease rather than increase in patients with AA.

Copyright (C) 2005 S. Karger AG, Basel

\section{Introduction}

Circulating platelets are heterogeneous with respect to their size, density and reactivity. The elevated mean platelet volume (MPV) has been proposed by many authors as a risk factor for ischemic heart disease $[1,2]$. In

\section{KARGER}

Fax +4161306 1234 E-Mail karger@karger.ch www.karger.com
(C) 2005 S. Karger AG, Basel

$1424-8832 / 05 / 0346-0269 \$ 22.00 / 0$

Accessible online at: www.karger.com/pht
Akihiro Ihara

Department of Hematology, National Hospital Organization, Kure Medical Center 3-1 Aoyama-cho, Kure

Hiroshima 737-0023 (Japan)

Tel. +81 82322 3111, Fax +81 82323 9629, E-Mail a-ihara@kure-nh.go.jp 
the case of aortic aneurysm (AA), Balduini et al. [3] reported increased MPV and/or thrombocytopenia in patients with unruptured abdominal AA. It is generally accepted that large platelets are metabolically and enzymatically more active than small platelets $[4,5]$. The degree of platelet activation may be assessed by parameters such as the platelet count, MPV and the percentage of large platelets. AA has been considered to arise as a direct consequence of atherosclerosis, in which platelet activation plays an important role in the prethrombotic events leading to thrombin formation. We compared the platelet indexes in age-matched controls (AC), in young controls (YC) and in patients with AA to evaluate the physiology of platelet heterogeneity on thrombus formation. Furthermore, we measured the D-dimer and thrombin-antithrombin III complex (TAT) in the patients and AC to estimate the platelet activation and the presence of hypercoagulability.

\section{Materials and Methods}

The subjects recruited were 54 patients with AA (aged 39-89 years, mean age 73 years; 40 males, 14 females) over a 12 -year period from 1989 to 2000, including 23 abdominal AA, 20 thoracic $\mathrm{AA}$ and 11 thoracoabdominal aneurysms, as well as $120 \mathrm{AC}$ from the Kure City Aged Conference (aged 63-86 years, mean age 73 years; 61 males, mean age 74 years; 59 females, mean age 72 years), and 38 YC (aged 18-40 years, mean age 30 years; 20 males, 18 females) from hospital workers. Patients with acute complications, such as rupture, infection, renal failure and those undergoing fibrinolytic therapy were excluded from this study. Persons who suffered from anemia, diabetes mellitus, thrombocytopenia (platelet count below $\left.15 \times 10^{9} / 1\right)$ and those with a past history of ischemic heart disease or cerebral vascular disease were also excluded. The patients were divided into two groups and split at the lower limit of the normal range for platelet count, group A (platelet count more than $150 \times 10^{9} / 1 ; \mathrm{n}=36$ ) and group B (platelet count below $150 \times$ $10^{9} / 1 ; n=18$ ), because the lower limit of the normal range for the platelet count in the Sysmex Corporation is $150 \times 10^{9} / 1$.
After informed consent had been obtained, venous blood samples were taken from the patients and the controls in the morning into $7.5 \%$ edetic acid (EDTA) for the measurement of the platelet index, and into $3.2 \%$ trisodium citrate for D-dimer and TAT measurement. The platelet count, MPV, platelet-large cell ratio ( $\mathrm{P}$ $\mathrm{LCR}$ ) and platelet distribution width (PDW) were calculated using a blood cell analyzer (E-4000; Sysmex Corporation, Kobe, Japan). P-LCR is the percentage of large platelets, defined as the platelet volume exceeding $12 \mathrm{fl}$. Plasma D-dimer and TAT were assayed by ELISA using assay kits (Dimer test EIA, AGEN, Australia; Enzygnost TAT, Behringwerke, Germany). The samples for platelet indexes were kept at room temperature and measured within $3 \mathrm{~h}$; for D-dimer and TAT, aliquots of platelet poor plasma were stored in plastic tubes at $-80^{\circ} \mathrm{C}$ until measurement. The values of the indexes were expressed as the mean \pm standard deviation. Significances of individual differences were evaluated using the Scheffé test if ANOVA was significant. Statistical differences between the two groups were assessed using the Mann-Whitney U test. Correlations between the variables were determined by calculating Spearman's rank correlation coefficients. 'Group A', 'group B' and AC were compared with respect to the platelet indexes. Statview 5 for Macintosh was used for all statistics. Differences were considered significant at $\mathrm{p}<0.05$.

\section{Results}

\section{Platelet Indexes in $A C$ and $Y C$}

The mean values for platelet count of $\mathrm{AC}$ and $\mathrm{YC}$ were not different $\left(236.1 \pm 52.9 \times 10^{9} / 1\right.$ and $223.9 \pm 57.9 \times$ $10^{9} / 1$, respectively). MPV and PDW were larger in AC than in YC, but the difference was not significant (10.42 \pm 0.79 vs. $10.27 \pm 0.48 \mathrm{fl}$ and $11.90 \pm 1.45$ vs. $11.52 \pm$ $0.83 \mathrm{fl}$, respectively). However, P-LCR was significantly higher $(\mathrm{p}=0.0113)$ in $\mathrm{AC}(27.48 \pm 6.50 \%)$ than in YC $(24.25 \pm 5.53 \%)$. The platelet indexes were not different between males and females in AC.

Table 1. Mean platelet indexes in patients with $\mathrm{AA}$ and $\mathrm{AC}$

\begin{tabular}{llclrrr}
\hline & $\begin{array}{l}\text { Median age } \\
\text { years }\end{array}$ & $\begin{array}{l}\text { Patient } \\
\text { number }\end{array}$ & $\begin{array}{l}\text { PLT } \\
\times 10^{9} / 1\end{array}$ & \multicolumn{1}{c}{$\begin{array}{l}\text { MPV } \\
\text { fl }\end{array}$} & \multicolumn{1}{l}{$\begin{array}{l}\text { P-LCR } \\
\%\end{array}$} & \multicolumn{1}{l}{$\begin{array}{l}\text { PDW } \\
\text { fl }\end{array}$} \\
\hline AC & $72(61.5-82.5)$ & $120(59 / 61)$ & $236.1 \pm 52.9$ & $10.42 \pm 0.79$ & $27.48 \pm 6.50$ & $11.9 \pm 1.45$ \\
Group A & $74(64.5-83.5)$ & $36(6 / 30)$ & $247.1 \pm 71.5$ & $9.61 \pm 0.80$ & $21.43 \pm 6.22$ & $10.6 \pm 1.39$ \\
Group B & $75(67.5-82.5)$ & $18(5 / 13)$ & $122.0 \pm 25.4$ & $10.49 \pm 1.07$ & $28.94 \pm 8.19$ & $12.4 \pm 2.06$ \\
Total AA & $75(66.7-83.3)$ & $54(11 / 43)$ & $202.2 \pm 83.5$ & $10.00 \pm 1.01$ & $24.59 \pm 7.90$ & $11.40 \pm 1.83$ \\
\hline \multicolumn{7}{c}{ a Interquartile range is given in parentheses. } \\
\multicolumn{2}{l}{${ }^{\mathrm{b}}$ Female/male ratio is given in parentheses. } \\
\hline
\end{tabular}


Platelet Indexes in $A C$ and $A A$ Patients

The mean platelet index values of AC were $236.1 \pm$ $52.9 \times 10^{9} / 1$ for platelet count, $10.42 \pm 0.79 \mathrm{fl}$ for MPV, $27.48 \pm 6.50 \%$ for P-LCR, and $11.90 \pm 1.45 \mathrm{fl}$ for PDW. The mean values of $54 \mathrm{AA}$ patients were $202.2 \pm 83.5 \times$ $10^{9} / 1$ for platelet count, $10.00 \pm 1.01 \mathrm{fl}$ for MPV, 24.59 $\pm 7.90 \%$ for P-LCR and $11.40 \pm 1.83$ fl for PDW. The mean values of group A were $247.1 \pm 71.5 \times 10^{9} / 1$ for platelet count, $9.61 \pm 0.80 \mathrm{fl}$ for MPV, $21.43 \pm 6.22 \%$ for P-LCR and $10.68 \pm 1.39 \mathrm{fl}$ for PDW. The mean values of group B were $122.0 \pm 25.4 \times 10^{9} / 1$ for platelet count, $10.49 \pm 1.07 \mathrm{fl}$ for MPV, $28.94 \pm 8.19 \%$ for P-LCR and $12.47 \pm 2.06 \mathrm{fl}$ for PDW (table 1). The platelet count in group B was significantly lower $(\mathrm{p}<0.0001)$ than that in group A and in AC. MPV ( $p=0.0024$ and $<0.0001$, respectively), P-LCR ( $p=0.0012$ and $<0.0001$, respectively) and PDW ( $p=0.0006$ and 0.0005 , respectively) in group A were significantly lower than those in group B and AC. The platelet indexes in the $54 \mathrm{AA}$ patients were significantly lower than those in $\mathrm{AC}(\mathrm{p}=0.0005,0.0008,0.0031$, 0.0093 , respectively). There were no differences between group B and AC in MPV, P-LCR and PDW (table 2).

\section{Correlations among Platelet Indexes}

There were significantly inverse relationships between the platelet count and other indexes in the $54 \mathrm{AA}$ patients (MPV: $\rho=-0.271, p=0.0486$; P-LCR: $\rho=-0.287, p=$

Table 2. Significances of individual differences between the patient groups and $\mathrm{AC}$

\begin{tabular}{lcccl}
\hline & PLT & MPV & P-LCR & PDW \\
\hline Group A vs. group B & $<0.0001$ & 0.0024 & 0.0012 & 0.0006 \\
Group A vs. AC & NS & $<0.0001$ & $<0.0001$ & 0.0005 \\
Group B vs. AC & $<0.0001$ & NS & NS & NS \\
Total AA vs. AC & 0.0005 & 0.0008 & 0.0031 & 0.0093 \\
\hline
\end{tabular}

0.0367; PDW: $\rho=-0.355, p=0.0098)$, and in AC (MPV: $\rho=-0.294, p=0.0013$; P-LCR: $\rho=-0.298, p=0.0012$; PDW: $\rho=-0.341, p=0.0002$ ); however, no significant relationships were observed in group $\mathrm{A}, \mathrm{B}$ and $\mathrm{YC}$, as shown in table 3 . There were strong relationships among MPV, P-LCR and PDW in the four groups.

\section{D-Dimer and TAT in the Patients and the AC}

D-dimer levels of group B, A and AC were 1,732.3 \pm $2,447.2,679.3 \pm 518.2$ and $111.8 \pm 48.3 \mathrm{ng} / \mathrm{ml}(\mathrm{n}=91)$, respectively, being significantly higher in group B than in group $\mathrm{A}$ and $\mathrm{AC}(\mathrm{p}=0.0003$ and $<0.0001$, respectively). The TAT levels of group B, A and AC were $26.7 \pm 19.0$, $13.5 \pm 10.3$, and $3.79 \pm 6.28 \mathrm{ng} / \mathrm{ml}(\mathrm{n}=88)$, respectively, being significantly higher in group B than in group A and $\mathrm{AC}$ ( $\mathrm{p}=0.0001$ and $<0.0001$, respectively).

\section{Discussion}

In the present study, P-LCR in AC was significantly higher than that in YC. MPV, P-LCR and PDW were significantly lower in group A than in group B and AC. There were no differences between group $B$ and $A C$ with respect to MPV, P-LCR and PDW. The platelet indexes were significantly lower in the 54 AA patients than in AC. Platelet count was significantly inversely correlated with MPV, P-LCR and PDW in AC and in the 54 AA patients. However, in YC these correlations were not significant. In group $\mathrm{A}$ and $\mathrm{B}$, such correlations were not observed. Such findings had not been reported before.

Balduini et al. [3] reported increased MPV in unruptured AA (10.8 $\pm 1.0 \mathrm{fl})$ using NE-8000 (Sysmex Corporation), which was different to our results. However, our results showed that in 87 patients with angina pectoris who underwent coronary angiography, MPV was almost the same as that in the AA patients of Balduini et al. and in our AC (data not shown). Increased MPV was reported
Table 3. Correlation coefficiency between the platelet count and other platelet indexes in patients with AA and the controls

\begin{tabular}{|c|c|c|c|c|c|c|c|}
\hline & \multirow[t]{2}{*}{$\mathrm{n}$} & \multicolumn{2}{|l|}{ MPV } & \multicolumn{2}{|l|}{ P-LCR } & \multicolumn{2}{|l|}{ PDW } \\
\hline & & $\rho$ & $\mathrm{p}$ & $\rho$ & $\mathrm{p}$ & $\rho$ & $\mathrm{p}$ \\
\hline $\mathrm{AC}$ & 120 & -0.295 & 0.0013 & -0.298 & 0.0012 & -0.341 & 0.0002 \\
\hline YC & 38 & -0.122 & 0.495 & -0.137 & 0.446 & -0.235 & 0.191 \\
\hline Group A & 36 & -0.022 & 0.895 & 0.027 & 0.875 & -0.011 & 0.510 \\
\hline Group B & 18 & 0.044 & 0.856 & 0.042 & 0.861 & -0.038 & 0.876 \\
\hline Total AA & 54 & -0.271 & 0.0486 & -0.287 & 0.0368 & -0.355 & 0.0098 \\
\hline
\end{tabular}


in patients with angina pectoris [4]. Thus, it is suggested that smaller platelets than in the controls or in angina pectoris exist in the circulation of AA patients.

Larger platelets have been thought to be young platelets because it had been suggested previously that platelets decrease in size as they age in the circulation [5]. However, there are controversial reports about platelet aging and platelet size [6]. The significance of platelet heterogeneity under various pathophysiological conditions is not yet fully understood.

There is a significant inverse relationship between MPV and platelet count in healthy volunteers [7]. It has been considered that platelet production is regulated to maintain a constant functional platelet mass, giving a constant hemostatic potential [8]. We showed the same relationships in AC and in the 54 AA patients in the present study. During stimulated thrombopoiesis, there was an increase both in the platelet count and in platelet volume. Platelets produced under such conditions, so-called 'stress' platelets, show an increase in the MPV compared with the normal platelets [9]. Large platelets are metabolically and enzymatically more active than small platelets, as assessed by ex vivo aggregometry $[10,11]$. Irrespective of certain remaining controversies regarding the origin of platelet size heterogeneity, there is agreement that stress platelets are larger than steady-state platelets and have greater functional capacity than smaller platelets. A similar situation is seen in acute coronary syndromes [1]. However, it was also reported that MPV does not increase in stable coronary artery disease [12].

Thrombus formation is responsible not only for the acute manifestation of atherosclerosis, but also for the continuous progression of atheroma [13]. Increased larger platelets in $\mathrm{AC}$ of the present study might possibly be a result of age-related atherosclerosis, possibly entailing chronic platelet consumption at the site of the atherosclerotic plaque. Thrombus formation is generally strong in patients with $\mathrm{AA}$, as reflected by elevated $\mathrm{D}$-dimer and TAT $[14,15]$, especially in group B. The increase in platelet size was accompanied by a decrease in platelet count, and the life span of 'stress' platelets will be remarkably shortened and thus, as a compensatory response, thrombopoiesis may be strongly accelerated leading to the formation of lager platelets. Although this phenomenon was present in AA patients, the size was significantly smaller than that in AC in this study. In the group A patients, although accelerated thrombopoiesis could maintain the platelet count within the normal range, the larger platelets will decrease in number due to consumption. However, in the group B patients, the excess platelet consumption might possibly be due to chronic disseminated intravascular coagulation, as reflected in the remarkably elevated the D-dimer and TAT, ultimately entailing the fact that platelet count could not be maintained within the normal range. This is based on the assumption that platelets of all sizes would equally be prone to consumption. This is the reason for decreased platelet count and the normal platelet size.

The limitations of this study are its retrospective nature, the limited number of patients and the lack of detailed and documented clinical findings (such as aneurysmal size and complications) which could, therefore, not be correlated with the platelet parameters. However, we were able to estimate the aneurysmal size and volume by measuring D-dimer and TAT [15].

In conclusion, the platelet indexes decreased rather than increased when the platelet count was within the normal range in the group A patients, and were within the normal range when the platelet count decreased in the group B patients. This study is, to our knowledge, the first to study platelet heterogeneity of AA.

\section{Acknowledgements}

The Cardiovascular Disease Research Commission 10 KO-7 supported this study. Many thanks go to the Kure Aged Conference for their cooperation and to Miss Kazuko Nitta for her assistance and support. 


\section{References}

-1 Endler G, Klimesch A, Sunder-Plassmann H, Schillinger M, Exner M, Mannhalter C, Jordanova N, Christ G, Thalhammer R, Huber K, Sunder-Plassmann R: Mean platelet volume is an independent risk factor for myocardial infarction but not for coronary artery disease. $\mathrm{Br}$ J Haematol 2002;117:399-404.

- 2 Mathur A, Robinson MS, Cotton J, Martin JF, Erusalimsky JD: Platelet reactivity in acute coronary syndromes: evidence for differences in platelet behaviour between unstable angina and myocardial infarction. Thromb Haemost 2001;85:989-994.

-3 Balduini Cl, Salvini M, Montani N, Noris P, Sepedini P, Belleti S, Gamba G: Activation of the hemostatic process in patients with unruptured aortic aneurysm before and in the first week after surgical repair. Haematologica 1997;82:581-583.

-4 Pizzulli L, Yang A, Martin JF, Luderitz B: Changes in platelet size and count in unstable angina compared to stable angina or non-cardiac chest pain. Eur Heart J 1998;19:80-84.
5 Thompson CB, Love DG, Quinn PG, Valeri CR: Platelet size does not correlate with platelet age. Blood 1983;62:487-494.

-6 Levin J, Bessman JD: The inverse relationship between platelet volume and platelet number. J Lab Clin Med 1983;101:295-307.

7 Thompson CB, Jakubowski JA: The pathophysiology and clinical relevance of platelet heterogeneity. Blood 1998;72:1-8.

8 Tong M, Seth P, Penington DG: Proplatelets and stress platelets. Blood 1987;59:522-528.

-9 Karpatkin S, Strick N: Heterogeneity of human platelets. V. Differences in glycolytic and related enzymes with possible relation to platelet age. J Clin Invest 1972;51:1235-1243.

10 Corash L, Tau H, Gralnick HR: Heterogeneity of human whole blood platelet subpopulations. I. Relationship between buoyant density, cell volume, and ultrastructure. Blood 1977;49: 71-87.
11 van der Loo B, Martin JF: A role for changes in platelet production in the cause of acute coronary syndromes. Arterioscler Thromb Vasc Biol 1999;19:672-679.

12 Haflbmayer WM, Haushofer A, Radek J, Schon R, Deutsch M, Fischer M: Platelet size, fibrinogen and lipoprotein (a) in coronary heart disease. Coron Artery Dis 1995;6:397402.

13 Nachman RL: Thrombosis and atherogenesis: molecular connections. Blood 1992;79:18971906.

14 Ihara A, Kawamoto T, Matsumoto K, Kawamoto J, Katayama A, Yoshitatsu M, Izutani H, Ihara K: Relationship between hemostatic markers and circulating biochemical markers of collagen metabolism in patients with aortic aneurysm. Pathophysiol Haemost Thromb 2003;33:221-224.

15 Nomura F, Ihara A, Yoshitatsu A, Tamura K, Katayama A, Ihara K: Relationship between coagulation cascade, cytokine, adhesion molecule and aortic aneurysm. Eur J Cardiothorac Surg 2003;23:1034-1039. 